\title{
Skeletal Pathology of Farm-Reared Obese Juvenile Blue Foxes (Vulpes lagopus)
}

\section{Anne-Mari Mustonen ${ }^{\mathrm{a}, \mathrm{b}}$, Dennis F. Lawlerc, Leena Aholad, Tarja Koistinen $^{\mathrm{d}, \mathrm{e}}$, Liisa Jalkanen ${ }^{\mathrm{f}}$, Jaakko Mononene, Marja-Leena Lamidig, Petteri Nieminen ${ }^{a, b}$}

a University of Eastern Finland, Faculty of Health Sciences, School of Medicine, Institute of Biomedicine/Anatomy, P.O. Box 1627, Fl-70211, Kuopio, Finland

${ }^{b}$ University of Eastern Finland, Faculty of Science and Forestry, Department of Environmental and Biological Sciences, P.O. Box 111, Fl-80101, Joensuu, Finland

c Illinois State Museum Research and Collections Center, 1011 East Ash St., Springfield, IL 62703, USA

d University of Eastern Finland, Faculty of Science and Forestry, Department of Environmental and Biological Sciences, P.O. Box 1627, Fl-70211, Kuopio, Finland

e Natural Resources Institute Finland (Luke), Green Technology, Halolantie 31A, Fl71750, Maaninka, Finland

${ }^{f}$ Punaturkki Veterinary Clinic, Satamakatu 20, Fl-70100, Kuopio, Finland

$g$ University of Eastern Finland, Faculty of Health Sciences, P.O. Box 1627, FI-70211, Kuopio, Finland

With 8 figures \& 1 table Received June, accepted for publication September 2017

\section{Abstract}

Orthopedic abnormalities of farmreared blue foxes (Vulpes lagopus) have increased recently, creating new concerns about their welfare. Therefore, skeletal condition of obese juvenile blue foxes was evaluated for relationships to degree of obesity. Two pilot study groups included less obese foxes $(\mathrm{N}=5)$ and more obese foxes $(\mathrm{N}=5)$; the latter group had visible carpal joint laxity and locomotor deficits. The principal aims were to examine forelimb deformities and abnormal locomotion J. Vet. Anat. in light of degree of obesity. Overt and incipient (mild or developing) pathology were prevalent and reflected degree of obesity. It is likely that genetic selection and feeding practices were primary underlying problems, but disrupted mineral nutrition and housing practices may have been involved as well. These observations underscore the importance of new actions and additional studies of breeding, nutrition, and housing practices, with the ultimate goal of enhancing the welfare of farmed foxes. 
Keywords: blue fox, obesity, radio- graphy, skeletal pathology, Vulpes lagopus.

\section{Introduction}

Eight decades of diet restriction research have contributed significantly to the understanding of obesity. Body fat now is recognized as an active endocrine organ with the capacity to influence metabolism by (a) contributing to oxidative stress; (b) secreting several hormones; and (c) releasing inflammatory cytokines (Laflamme 2012). Excess body fat in domestic dogs (Canis lupus familiaris) increases risk of (a) glucose intolerance and insulin resistance (Larson et al. 2003; de Godoy and Swanson 2013); (b) osteoarthritis; (c) earlier onset of aging-related diseases; (d) shortened lifespan (Kealy et al. 2002; Lawler et al. 2008); (e) reduced respiratory tidal volume, as well as increased respiratory rate and bronchoreactivity (Manens et al. 2012).

The blue fox is a color variant of the wild arctic fox (Vulpes lagopus). Blue foxes have been farm-reared for approximately 100 generations (Einarsson and Skrede 1989). Size, body mass, and obesity of blue foxes have increased dramatically in recent decades due to strong selec- tion for large pelt size, and unrestricted feeding (body mass $5-7 \mathrm{~kg}$ in Nes et al. 1988; 13-14 kg in Kempe et al. 2009, 2013; 13-19 kg in Korhonen et al. 2014). Today, body condition at pelting most often is obese to extremely obese (Kempe et al. 2009).

Welfare problems that may relate to obesity, such as foot deformities and abnormal locomotion, are observed frequently on blue fox farms (Kempe et al. 2010; Ahola et al. 2012). In the survey by Ahola et al. (2012), 47\% of Finnish foxes especially the blue fox showed degrees of abnormal locomotion, while $23 \%$ displayed severe forelimb bending. Kempe et al. (2010) observed that $67 \%$ of juvenile blue foxes had poor or very poor forelimb structure.

In this primarily observational pilot study, full skeletons of ten blue foxes were evaluated. The aims were: (a) examine the relationship of visible skeletal pathology to observed limb deformities and locomotor deficits of farm-reared blue foxes; (b) evaluate the contributing role of excessive obesity. The hypotheses were: (a) skeletal pathology contributes to carpal joint laxity and abnormal locomotion; (b) obesity causes or exacerbates musculoskeletal conditions of juvenile blue foxes. 


\section{Materials and Methods}

\section{Experimental animals and hous- ing}

Ten male farm-reared blue foxes were selected at age seven months, based on their body condition, forelimb structure, and locomotor characteristics as of 8 December 2011. The foxes had been housed as sibling pairs in $1.2 \mathrm{~m}^{2}$ wire-mesh cages with an elevated observation platform and at least one activity object. The cages were in outdoor sheds at natural ambient temperature and photoperiod, in Eastern Finland $\left(63^{\circ} \mathrm{N}, 2^{\circ} \mathrm{E}\right)$.

The foxes were fed ad libitum with commercial fur animal diets (YläKarjalan Rehu, Valtimo, Finland; raw protein $9.1-10.7 \%$; raw fat $10.8-11.6 \%$; raw carbohydrates $15.7-17.6 \%$ of fresh weight; metabolizable energy 6.9-7.4 MJ/kg fresh weight). Vitamin-mineral supplements were added to the diet to approximate official recommendations for foxes (Finnish Fur Breeders' Association 2011). Water was provided ad libitum with an automatic watering system.

Fox body condition scores were evaluated visually by one researcher (TK) on 8 December 2011, according to Kempe et al. (2009), as 1 $=$ very thin; $2=$ thin; $3=$ ideal; $4=$ heavy; $5=$ extremely fat. Carpal laxi- ty was evaluated by TK based on WelFur assessment categories $0=$ no bent feet; 1 = slightly bent feet; 2 = severely bent feet (WelFur 2015). Locomotion was evaluated by TK based on WelFur assessment categories (WelFur 2015).

Five less obese foxes (body condition score 3-4) had normal to mildly abnormal forelimb structure (WelFur score 0-1) and no clear locomotor deficit or unwillingness to move. Five more obese foxes (body condition score 5) had severely bent forelimbs (WelFur score 2) and abnormal locomotion and/or unwillingness to move. Since the study location was a commercial fox farm, no non-obese foxes were available and the selection process could not be randomized.

\section{Euthanasia and radiography}

All the foxes were reared on a commercial farm until they were harvested at age seven months, during the normal pelting season. They were sacrificed by electrocution according to recommended farming practices (Council of the European Union 2009), on the same day that their body condition, forelimb conformation, and locomotion were evaluated. No animal ethics license was required, based on the instructions of the National Animal Experiment Board. The foxes were pelted manually and the car- 
casses were transported to the University of Eastern Finland to be frozen at $-20^{\circ} \mathrm{C}$.

Radiographic examination was done in a single-blind manner at the Tuhatjalka Veterinary Clinic (Kuopio, Finland) by an experienced veterinarian (LJ). The radiographs were taken using the Sedecal APRVET model no. A6504-01 (Algete, Spain). Multiple radiographic images were taken of each cadaver. The spine was examined using a lateral projection focused at mid-lumbar, and forelimb images included cervical and thoracic vertebrae. The cranium and forelimbs were imaged using ventrodorsal and lateral projections, both centered on the elbow joints. The hind limbs were examined using two ventrodorsal projections, focused on the hips and tibias. The radiographs were evaluated by an experienced veterinarian (DL) who was unaware of group assignment.

\section{Skeletal clearing and skeletal analysis}

After radiography, the carcasses were weighed, and initial soft tissue clearing was done to remove abdominal and thoracic soft tissue. The remainder of each carcass was frozen and shipped on dry ice to the Illinois State Museum Research and Collections Center (Springfield, IL, USA). The carrier replenished dry

J. Vet. Anat. ice as required, and the carcasses arrived frozen and intact. They were transferred to $\mathrm{a}-4^{\circ} \mathrm{C}$ freezer until further processing.

Detailed skeletal clearing was completed by thawing for 24 hours at room temperature, manual defleshing, and disarticulation (DL). Disarticulated skeletal components were incubated in covered, waterfilled stainless steel containers at $45^{\circ} \mathrm{C}$, with periodic discard of macerated remaining soft tissue, and water replacement. Following maceration, defatting was continued as needed in $20 \%$ ammonia solution at room temperature, followed by drying for about seven days.

Skeletal observations were characterized as normal, incipient pathology, or pathology. Incipient pathology was contrasted from overt pathology by being (a) occult by direct physical examination and radiography; (b) recognized occasionally at gross necropsy and recognized frequently on cleared bone; (c) evidently early or very mild stages of development (Lawler and Evans 2016).

Pathology was graded as present or absent. Findings for right and left sides of the body first were classified separately, but if overt/incipient pathology was identified, the structure diagnosis was assigned ac-

Vol. 10, No. 2, (2017) 51 - 74 
cording to the worse side. A pathological finding even in the minority of the ribs (or other skeletal structures with multiple parts) was considered sufficient for this anatomical region to be classified as pathological. All structures were photographed.

\section{Statistical analysis}

The goal of statistical evaluation was to estimate differences between less obese and more obese foxes, since degrees of obesity influence health and longevity of dogs (Lawler et al. 2008). Effects of obesity on prevalence of radiographic and skeletal findings were tested by binary logistic regression with generalized estimating equations, to account for the correlation structure of the data due to the repetitions (SPSS v19.0 software, IBM, Armonk, NY, USA). Pathology classifications were selected as the response, with obesity and anatomical region as predictors. Radiographic observations were tested as pooled data, and skeletal observations (axial skeleton, forelimbs, hind limbs) were tested separately. The vertebral column also was tested separately from the axial skeleton, with vertebral groups as predictors.

In some cases, the distribution of either incipient or overt pathology between the less and more obese foxes could not be tested with the model because there were too few assignments to a particular classification in the group and/or anatomic area. In these instances, the model was simplified by not including the interaction of group-by-anatomic area. The results are presented as $\mathrm{N}$ of foxes in each category (Table 1).

Linear regression analysis was done on the combined and average pathology scores of each individual as dependent variables and the carcass weight as the independent variable. The weights of skinned carcasses were compared between the groups using the Mann-Whitney $U$-test, as the data were not normally distributed. The $p<0.05$ was considered statistically significant.

\section{Results}

\section{Carcass weights}

All ten carcasses were much larger, with much more body fat than is observed in free-roaming $V$. lagopus. Weights of skinned carcasses differed between the groups (less obese median $8.96 \mathrm{~kg}$; more obese median $13.08 \mathrm{~kg}$; Mann-Whitney $U$ test, $p=0.009$ ). The regression analyses for carcass weights and pathology scores of combined anatomical areas were not statistically significant $(p=0.111-0.123)$. 


\section{Radiography}

Radiographic examinations suggested one or more narrowed intervertebral disk spaces in four less obese foxes and one more obese fox. However, the observations could not be confirmed from disarticulated skeletal components.

Scapular radiography revealed glenoid subchondral sclerosis (three less obese; two more obese) and periarticular bony prominence (one more obese). Humeral shoulder articulations suggested flattened articular surface (one less obese) and prominent articular margin (one less obese). Incongruent elbow joint spaces were observed in four more obese foxes, and wide carpal joint space was suggested in one more obese fox. One more obese fox had a healing humeral shaft fracture that caused a short and deformed bone, elbow osteoarthritis (Fig 1), and mild deformity of the carpal joint.

Hip radiography suggested shallow acetabulum (two less obese; three more obese) with subchondral sclerosis (three less obese; three more obese), and prominent articular margin (one more obese). The femoral articular margin revealed circumferential osteophytes (three less obese; two more obese). Caudal femoral neck osteophytes (three less obese; two more obese) also were observed. Other observations J. Vet. Anat. included (a) hip joint laxity (three less obese) or subluxation (two less obese; five more obese); (b) flattened or misshaped femoral head (four less obese; four more obese); (c) prominent femoral head articular margin (one less obese).

The distribution of normality vs. pathological radiographic observations differed significantly according to group and anatomic location (generalized linear model with binary logistic; experimental group $p<$ 0.001 , anatomic region $p<0.001$, interaction $p=0.484$ ). The frequency of suspected abnormal observations was higher in the more obese group (44 vs. 48\%).

\section{Skeletal findings: Axial skeleton}

The entire skeleton of each of the ten foxes was evaluated (DL) without knowledge of group assignment. To facilitate reader evaluation of welfare-associated observations, sums for normality, incipient pathology, and overt pathology are reported for each structure (Table 1), along with a qualitative summary of primary observations in the text.

Skull: Pathology observations included (a) fragility, porosity, thin bone structure; (b) dental alveolar wall thinning; (c) perialveolar prominence or overt rim formation; (d) rough perialveolar bone; (e) prominent alveolar margin (Fig 2).

Vol. 10, No. 2, (2017) 51 - 74 
Thorax and Vertebrae: Pathology observations included (a) fragile ribs and costochondral flaring (Fig 3); (b) vertebral articular osteophytes. Incipient pathology included (c) prominent/sharp vertebral articular margin or periarticular rim. Vertebral lateral asymmetry occurred at high frequency.

Degree of obesity did not affect distribution of normality vs. incipient pathology in the axial skeleton (group $p=0.668$, region $p<0.001$ ). The distribution of normality $v s$. overt pathology differed significantly based on group and location (group $p=0.001$, region $p<0.001$, interaction $p=0.515)$. The frequency of pathological observations was higher in the more obese group. The distribution of observations also differed when categories of pathology were pooled (normality vs. pooled incipient and overt pathology; group $p<0.001$ [less obese $48 \%$; more obese $62 \%$ ], region $p<$ 0.001 , interaction $p=0.550$ ).

There was no effect of obesity on vertebrae (normality vs. incipient pathology: group $p=0.668$, region $p=0.005$; normality vs. pooled incipient and overt pathology: group $p$ $=0.548$, region $p=0.002$ ).

\section{Skeletal findings: Appendicular skeleton, forelimbs}

J. Vet. Anat.
Scapula: Pathology observations included (a) rough or irregular articular or periarticular bone; (b) deepened caudolateral glenoid fossa. Incipient pathology included (c) prominent/sharp/rimmed articular margin; (d) prominent or thickened periarticular bone; (e) focal delayed ossification.

Humerus: Pathology observations included:

(a) prominent/sharp/thickened articular margin; (b) prominent or rimmed periarticular margin (distal humerus); (c) increased shaft curvature or distorted shaft (Supplementary Figure S1A); (d) rough/ irregular bone surface; (e) articular surface depression; (f) healed fracture (Supplementary Figure S1A). Incipient pathology included (g) prominent periarticular margin (proximal humerus); (h) rim at articular/periarticular margin (proximal humerus); (i) flattened or thickened articular margin (proximal humerus); (j) thickened lateral margin of the intertubercular groove; (k) focal abnormal wear (distal humerus).

Radius: Pathology observations included proximal (a) osteophytes; (b) prominent/thickened articular/ periarticular margin (Fig 4a); (c) periarticular prominence or proliferation; (d) articular surface depression; (e) bone shaft increased curvature (Fig 4a) or distortion; distal 
(f) rough articular bone surface or surface defect; (g) periosteal reaction; (h) wide, rough, and indistinct epiphyseal bone (Fig 4a, Supplementary Figure S2). Incipient pathology included (a) incomplete articular margin ossification with mild rim; (b) prominent periarticular margin; (c) irregular articular margin; (d) irregular bone surface.

UIna: Pathology observations included (a) osteophytes (Supplementary Figure S1B); (b) periosteal reaction; (c) increased shaft curvature or distortion; (d) impinged/distorted articular surface; (e) rough, thickened bone surface; (f) wide, rough, indistinct/elongated/ thickened epiphyseal or metaphyseal bone. Incipient pathology included (g) thickening or prominence of the periarticular margin; (h) rimming of articular/periarticular margin; (i) prominent articular margin; (j) incomplete ossification of articular surface. The more obese fox with a partly healed humeral shaft fracture (Supplementary Figure S1A) also revealed significant osteoarthritis and deformity of the associated proximal radius and ulna (Supplementary Figure S1B).

Distal limb: Pathology observations in phalanges consisted only of bone porosity. Incipient pathology consisted of prominent articular margin. Among metacarpals and

metatarsals, periarticular prominence was the only pathology observation, while rough bone surface occurred as incipient pathology. All carpal joint bones were normal. Incomplete ossification was observed in tarsal joint bones.

Obesity influenced the distribution of normality and incipient pathology in the forelimbs (group $p=0.027$, region $p<0.001$ ), with a higher frequency of incipient pathology in the more obese group. The distribution of normality $v s$. overt pathology differed significantly (group $p<$ 0.001 , region $p<0.001$, interaction $p=0.999)$. The distribution also was different when the categories of pathology were pooled (normality vs. pooled incipient and overt pathology; group $p<0.001$ [less obese 52\%; more obese $64 \%$ ], region $p<0.001$, interaction $p=$ 1.000).

\section{Skeletal findings: Appendicular skeleton, hind limbs}

Acetabulum: Pathology observations consisted of medial or dorsomedial acetabular periarticular rim. Incipient pathology included (a) prominent/rough/sharp lateral articular margin (Supplementary Figure S3); (b) rough or incompletely ossified articular surfaces; (c) fossa new bone deposition suggesting enthesiophytes.

\section{J. Vet. Anat.}


Femur: Pathology observations included (a) caudal femoral neck osteophyte; (b) bony filling/ thickening of the dorsal femoral neck; (c) rough periarticular bone surfaces; (d) prominent/sharp articular/ periarticular margins (Supplementary Figure S4); (e) incomplete ossification; (f) rough or porous bone; (g) wide, rough surfaces of epiphyseal and metaphyseal bone (Supplementary Figure S4); (h) increased femoral shaft curvature (Fig 4b); (i) mild bony proliferation of the patella. Incipient pathology included (j) femoral head flattening; $(k)$ rough, irregular periarticular margins.

Tibia, fibula: Pathology observations included (a) prominent/rough articular/periarticular margin; rough/prominent bone surface; (c) increased shaft curvature; (d) incomplete ossification; (e) articular surface depression or suspected erosion; ( $f$ ) wide, rough, and indistinct epiphyseal and metaphyseal bone. Incompletely fused tibial crest occurred as incipient pathology. Fibular observations included (g) wide, rough, and indistinct epiphyseal and metaphyseal bone; (h) incomplete ossification; (i) increased shaft curvature or bowing.

The distribution of normality vs. overt pathology in the hind limbs differed significantly according to group and location (group $p<$ J. Vet. Anat.
0.001 , region $p<0.001$, interaction $p=0.875$ ), with the more obese group having higher frequency of pathology observations. The distribution also was significantly different when the categories of pathology were pooled (normality vs. pooled incipient and overt pathology; group $p<0.001$ [less obese $48 \%$; more obese $58 \%$ ], region $p<$ 0.001 , interaction $p=0.876$ ).

\section{Discussion}

\section{Radiography}

Direct examination of cleared bones is known to be more sensitive than radiography for detecting pathological changes (Lawler and Evans 2016). In the blue foxes, routine radiographs accurately reflected direct observations only when pathology was at least moderately advanced. Similar outcomes occurred in a previous study of shoulder joints of gray wolves (Canis lupus lupus; Lawler et al. 2016a). Suwankong et al. (2006) reported that computed tomography and magnetic resonance imaging of canine degenerative lumbosacral stenosis aligned well with one another, but both agreed less well with direct observations at surgery.

Interpretation of radiographs in this study likely was complicated by (a) inability to achieve completely correct positioning flexion secondary to large focal subcutaneous fat depos-
Vol. 10, No. 2, (2017) 51 - 74 
its; (b) joint alterations caused by excessive body weight on an immature skeleton. Radiographic interpretation also may be complicated by lack of species-specific reference data (Lawler and Evans 2016); post-mortem rigor mortis (Lawler et al. 2016a); and forces applied during pelting.

Incipient skeletal pathology of farmreared canids likely would be interpreted from radiography only as increased bone density (Lawler et al. 2015), or as within normal limits. Thus, radiography alone is insufficient as a diagnostic approach to assessing orthopedic disease in farm-reared canids.

\section{Skeletal effects}

Skeletal pathology often is subtle at early or mild stages. Thus, diagnoses by any approach are partly subjective. An observation at some early point could be diagnosed as a minor anatomic variant, later becoming suspected incipient pathology, or overt pathology at a still more advanced stage. Therefore, outcomes of evaluation depend partly on age of the individual at examination, stage of the pathology, and rate of progression. In the context of age, the observed frequencies of pathology in these seven-month juvenile blue foxes were unexpectedly high.
Previous data on musculoskeletal disorders of juvenile blue foxes are scarce. Korhonen et al. (2015) reported that evaluation of carpal and elbow joints did not reveal damage or disease, and no curving of ulna or radius was noted. These observations suggest the possibility of interacting or co-contributing causes for the blue fox observations.

We observed few changes in metapodial, carpal, or tarsal bones, and the bone curvatures that we documented were insufficient (subjectively) to cause locomotor disorders. The large sizes and young ages of the blue foxes, and the fact that long bone deformity was mild, suggest a hypothesis that forelimb bending was related mainly to tendon and ligament stress because body weight was excessive and thus could not be supported by stillmaturing skeletal elements. The extreme size departure from that of wild arctic foxes (Audet et al. 2002) results at least partially from genetic selection for large size, to yield a large pelt (Kempe et al. 2013).

Housing condition is another factor that requires new studies. Korhonen et al. (2001) documented a tendency for better leg structure in blue foxes that were reared in large earthen-floor pens $\left(15 \mathrm{~m}^{2}\right)$ rather than in smaller wire-mesh cages $\left(0.5 / 1.3 \mathrm{~m}^{2}\right)$. The possibility of interVol. 10, No. 2, (2017) 51 - 74 
Skeletal pathology of obese blue foxes acting or co-contributing causes for the observations is suggested strongly.

\section{Nutritional influences}

Obesity is a significant risk for musculoskeletal disorders of domestic dogs, especially osteoarthritis (Kealy et al. 2000; Marshall et al. 2009). Dämmrich (1991) documented that overnutrition can lead to growth rates that are too rapid for proper skeletal development. In largebreed dogs, carpal hyperextension, increased distal radial and ulnar size, and roughness of periosteal and medullary contours, are among changes that can result from excessively rapid growth (Hedhammar et al. 1974). In rapidly growing puppies, malnutrition or overnutrition can lead to pathology of extensor and flexor muscle groups and, thus, joint laxity (Çetinkaya et al. 2007). The blue foxes revealed compatible joint pathology.

In addition to overnutrition, the findings also suggest disrupted mineral nutrition, again raising the possibility of interacting or co-contributing causes. Calcium:phosphorus (Ca: P) imbalance can induce severe disturbances of skeletal development, growth, and bone mineralization in large dog breeds (Schoenmakers et al. 2000). Korhonen et al. (2015) have connected forelimb bending with dietary Ca:P 1.5:1 in J. Vet. Anat.
Mustonen et al.

juvenile blue foxes, although confirming data are needed (Korhonen et al. 2005).

Unfortunately, the composition of the diet in the present study could not be examined in detail. Some of the observations, such as skull fragility, could derive from nutritional secondary hyperparathyroidism (de Fornel-Thibaud et al. 2007), underscoring the need for additional nutritional studies of farmed foxes.

An observation that likely was not obesity-related was the fiber-like shredding of costochondral bone that, based on experience, probably represents a processing effect of hot water maceration on the margins of inadequately mineralized bone.

\section{Vertebral observations}

Some cervical, thoracic, and lumbar vertebrae displayed at least incipiently pathological osteoarthritic changes in all foxes. Vertebral spinous process deviations were frequent; these may be incidental or pathological (Lawler et al. 2016b), but further clarifying diagnostics were not available for this pilot study.

Vertebral asymmetry can involve articular processes and surfaces, the spinous process, the vertebral arch, or the vertebral body. These

Vol. 10, No. 2, (2017) 51 - 74 
variants are common among skeletal remains of dogs and other canids (Lawler et al. 2016b and unpublished data), and appear to represent normal variation. Vertebrae from $V$. lagopus, $V$. vulpes, Urocyon cinereoargenteus, Canis latrans, and C. lupus familiaris, frequently reveal the same asymmetry without other pathology (Lawler DF, unpublished from specimens curated at the Illinois State Museum). Kharlamova et al. (2010) have demonstrated that skull, pelvis, and limbs of farm-reared silver foxes display directional asymmetry.

\section{Conclusions}

Incipient and overt skeletal pathology were common in these late juvenile blue foxes. Multiple skeletal components were involved. Obesity likely is the main direct etiological factor, but interacting or cocontributing influences cannot be excluded. Feeding practices now should be re-evaluated, to ensure that foxes do not develop overt locomotor and conformational abnormalities.

The data also indicate that genetic selection criteria for farmed fox rearing need to be redirected. In particular, selection for large body size may be significantly predisposing to other welfare and health concerns, and this practice needs to be reconsidered. Housing practices may require revisions to facilitate increased daily locomotor activity for farmed foxes.

Dietary mineral balance as it relates to whole diet nutrient content and balance may be an underrecognized factor that contributes negatively to welfare and comfort, and thus new controlled nutritional studies clearly are needed urgently, likely along with evaluation for interacting genetic, nutritional, and housing influences. Studies of jointrelated soft tissues would be useful to clarify histological characteristics of tendons, ligaments, and joint capsules of foxes that have visible carpal joint deformity.

\section{Acknowledgments}

The technical help of Jaana Auvinen, Kasper Heikkilä, Hobo Kukkonen, Olli Salmensuu, and the staff at the fur farm is greatly acknowledged. Labor allocated to this project by LA, TK, and JM, the costs for obtaining the carcasses and their delivery to the USA, as well as the radiographs were financially supported by the WelFur project funded by the European Fur Breeders' Association. The funding source had no involvement in the study design, in the collection, analysis and interpretation of data, in the writing of the report or in the 
Skeletal pathology of obese blue foxes

decision to submit the article for publication.

\section{References}

Ahola, L.K., Huuki, H., Hovland, A.L., Koistinen, T., Mononen, J. (2012): WelFur - foxes: the interobserver reliability of the WelFur health measures, and the prevalence of health disorders on fox farms during the growth period. In: Larsen, P.F., Møller, S.H., Clausen, T., Hammer, A.S., Lássen, T.M., Nielsen, V.H., Tauson, A.H., Jeppesen, L.L., Hansen, S.W., Elnif, J., Malmkvist, J., (Eds.). Proceedings of the $X^{\text {th }}$ International Scientific Congress in Fur Animal Production. Wageningen Academic Publishers. Wageningen, pp. 441-447.

Audet, A.M., Robbins, C.B., Larivière, S. (2002): Alopex lagopus. Mamm. Species No. 713: 1-10.

Çetinkaya, M.A., Yardimci, C., Sağlam, M. (2007): Carpal laxity syndrome in forty-three puppies. Vet. Comp. Orthop. Traumatol. 20: 126-130.

Council of the European Union. (2009): Council regulation (EC) No 1099/2009 of 24 September 2009 on the protection of animals at the time of killing. Off. J. European Union 52(L 303): 1-30.
Mustonen et al.

Dämmrich, K. (1991): Relationship between nutrition and bone growth in large and giant dogs. J. Nutr. 121: S114-S121.

de Fornel-Thibaud, P., Blanchard, G., Escoffier-Chateau, L., Segond, S., Guetta, F., Begon, D., Delisle, F., Rosenberg, D. (2007): Unusual case of osteopenia associated with nutritional calcium and vitamin $\mathrm{D}$ deficiency in an adult dog. J. Am. Anim. Hosp. Assoc. 43: 5260.

de Godoy, M.R.C., Swanson, K.S. (2013): Companion Animals Symposium: Nutrigenomics: Using gene expression and molecular biology data to understand pet obesity. J. Anim. Sci. 91: 2949-2964.

Einarsson, E.J., Skrede, A. (1989): Avl og Fôring av Rev. Landbruksforlaget, Otta.

Finnish Fur Breeders' Association. (2011): Operation handbook 2010-2011. In: Fur 2011 Calendar. Saga Furs and Finnish Fur Breeders' Association. Vantaa, pp. 30152.

Hedhammar, A., Wu, F.-M., Krook, L., Schryver, H.F., de Lahunta, A., Whalen, J.P., Kallfelz, F.A., Nunez, E.A., Hintz, H.F., Sheffy, B.E., Ryan, G.D. (1974): Overnutrition and skeletal disease: 
An experimental study in growing Great Dane dogs. Cornell Vet. 64 (suppl. 5): 5-160.

Kealy, R.D., Lawler, D.F., Ballam, J.M., Lust, G., Biery, D.N., Smith, G.K., Mantz, S.L. (2000): Evaluation of the effect of limited food consumption on radiographic evidence of osteoarthritis in dogs. J. Am. Vet. Med. Assoc. 217: 1678-1680.

Kealy, R.D., Lawler, D.F., Ballam, J.M., Mantz, S.L., Biery, D.N., Greeley, E.H., Lust, G., Segre, M., Smith, G.K., Stowe, H.D. (2002): Effects of diet restriction on life span and age-related changes in dogs. J. Am. Vet. Med. Assoc. 220: 1315-1320.

Kempe, R., Koskinen, N., Peura, J., Koivula, M., Strandén, I. (2009): Body condition scoring method for the blue fox (Alopex lagopus). Acta Agric. Scand. 59A: 85-92.

Kempe, R., Koskinen, N., Mäntysaari, E., Strandén, I. (2010): The genetics of body condition and leg weakness in the blue fox (Alopex lagopus). Acta Agric. Scand. 60A: 141-150.

Kempe, R., Koskinen, N., Strandén, I. (2013): Genetic parameters of pelt character, feed efficiency and size traits in Finnish blue fox J. Vet. Anat.
(Vulpes lagopus). J. Anim. Breed. Genet. 130: 445-455.

Kharlamova, A.V., Trut, L.N., Chase, K., Kukekova, A.V., Lark, K.G. (2010): Directional asymmetry in the limbs, skull and pelvis of the silver fox ( $V$. vulpes). J. Morphol. 271: 1501-1508.

Korhonen, H., Jauhiainen, L., Niemelä, P., Harri, M., Sauna-aho, R. (2001): Physiological and behavioural responses in blue foxes (Alopex lagopus): comparisons between space quantity and floor material. Anim. Sci. 72: 375-387.

Korhonen, H.T., Happo, M., Rekilä, T., Valaja, J., Pölönen, I. (2005): Effects of diet calcium: phosporus ratio and metabolizable energy content on development of osteochondrosis, foot bending and performance in blue foxes. Anim. Sci. 80: 325-331.

Korhonen, H.T., Eskeli, P., Lappi, T., Huuki, H., Sepponen, J. (2014): Effects of feeding intensity and $\mathrm{Ca}: P$ ratio on foot welfare in blue foxes (Vulpes lagopus). Open J. Anim. Sci. 4: 153-164.

Korhonen, H.T., Eskeli, P., Huuki, H., Sepponen, J. (2015): Foreleg bending in blue foxes (Vulpes lagopus) as evaluated by radiography. Open J. Vet. Med. 5: 61-67. 
Laflamme, D.P. (2012): Companion Animals Symposium: Obesity in dogs and cats: What is wrong with being fat? J. Anim. Sci. 90: 16531662.

\section{Larson, B.T., Lawler, D.F.,} Spitznagel, E.L. Jr., Kealy, R.D. (2003): Improved glucose tolerance with lifetime diet restriction favorably affects disease and survival in dogs. J. Nutr. 133: 2887-2892.

Lawler, D.F., Evans, R.H. (2016): Evaluation of femoral head and neck new bone from a grey wolf (Canis lupus lupus): When is it pathology? J. Vet. Anat. 9: 39-46.

Lawler, D.F., Larson, B.T., Ballam, J.M., Smith, G.K., Biery, D.N., Evans, R.H., Greeley, E.H., Segre, M., Stowe, H.D., Kealy, R.D. (2008): Diet restriction and ageing in the dog: major observations over two decades. Br. J. Nutr. 99: 793-805.

Lawler, D.F., Evans, R.H., Reetz, J.A., Sackman, J.E., Chase, K., Widga, C.C., Smith, G.K. (2015): Scapular glenoid observations of six Canis lupus dingo. J. Vet. Anat. 8: 47-58.

Lawler, D., Becker, J., Reetz, J., Goodmann, P., Evans, R., Rubin, D., Tangredi, B., Widga, C., Sackman, J., Martin, T., Kohn, L., Smith, G. (2016a): Pathology of grey wolf shoulders: Lessons in species and aging. Anat. Rec. 299: 1338-1347.

Lawler, D.F., Widga, C., Rubin, D.A., Reetz, J.A., Evans, R.H., Tangredi, B.P., Thomas, R.M., Martin, T.J., Hildebolt, C., Smith, K., Leib, D., Sackman, J.E., Avery, J.G., Smith, G.K. (2016b): Differential diagnosis of vertebral spinous process deviations in archaeological and modern domestic dogs. J. Archaeol. Sci. Reports 9: 54-63.

Manens, J., Bolognin, M., Bernaerts, F., Diez, M., Kirschvink, N., Clercx, C. (2012): Effects of obesity on lung function and airway reactivity in healthy dogs. Vet. J. 193: 217221.

Marshall, W.G., Bockstahler, B.A., Hulse, D.A., Carmichael, S. (2009): A review of osteoarthritis and obesity: current understanding of the relationship and benefit of obesity treatment and prevention in the dog. Vet. Comp. Orthop. Traumatol. 22: 339-345.

Nes, N., Einarsson, E.J., Lohi, O., Jarosz, S., Scheelje, R. (1988): Vackra Pälsdjur - och dessas Färggenetik. Scientifur, Hillerød.

Schoenmakers, I., Hazewinkel, H.A.W., Voorhout, G., Carlson, C.S., Richardson, D. (2000): Effect 
Skeletal pathology of obese blue foxes

of diets with different calcium and phosphorus contents on the skeletal development and blood chemistry of growing great danes. Vet. Rec. 147: 652-660.

Suwankong, N., Voorhout, G., Hazewinkel, H.A.W., Meij, B.P. (2006): Agreement between computed tomography, magnetic resonance imaging, and surgical findings in dogs with degenerative lumbosacral stenosis. J. Am. Vet. Med. Assoc. 229: 1924-1929.

WelFur. (2015): WelFur Welfare Assessment Protocol for Foxes. WelFur Consortium, Brussels, http://www.fureurope.eu/publication s/welfur-welfare-assessmentprotocol-for-foxes.

Corresponding author:

Dennis F. Lawler, dlawler11@yahoo.com 
Table 1. Pathological skeletal features of two groups of obese blue foxes.

\begin{tabular}{|c|c|c|c|c|c|c|c|}
\hline & \multirow[b]{2}{*}{ Structure } & \multicolumn{3}{|c|}{$\begin{array}{l}\text { Less Obese Foxes } \\
(\mathrm{N}=5)\end{array}$} & \multicolumn{3}{|c|}{$\begin{array}{l}\text { More Obese Foxes } \\
(\mathrm{N}=5)\end{array}$} \\
\hline & & $\mathrm{OP}(\mathrm{N})$ & $\mathrm{IP}(\mathrm{N})$ & $N(N)$ & $\mathrm{OP}(\mathrm{N})$ & $\mathrm{IP}(\mathrm{N})$ & $N(N)$ \\
\hline \multirow[t]{14}{*}{ Axial Skeleton } & skull, dorsal & 3 & & 2 & 3 & & 2 \\
\hline & skull, palatine & 3 & & 2 & 4 & & 1 \\
\hline & maxilla & 4 & & 1 & 5 & & \\
\hline & mandible & 2 & & 3 & 5 & & \\
\hline & teeth & & & 5 & & & 5 \\
\hline & sternebrae* & & & 5 & & & 4 \\
\hline & hyoid bones* & & & 5 & & & 4 \\
\hline & ribs & 2 & & 3 & 4 & & 1 \\
\hline & vertebrae cervical & 1 & 4 & & & 5 & \\
\hline & vertebrae thoracic & 1 & 4 & & 1 & 4 & \\
\hline & vertebrae lumbar & 1 & 4 & & & 5 & \\
\hline & sacrum & 1 & 3 & 1 & 2 & 2 & 1 \\
\hline & vertebrae coccygeal & & & 5 & & 1 & 4 \\
\hline & baculum* & & & 4 & & & 3 \\
\hline Appendicular Skeleton & phalanges & & & 5 & 1 & 1 & 3 \\
\hline \multirow[t]{16}{*}{ left, right hind limbs } & nails & & & 5 & & & 5 \\
\hline & retrieved sesamoids & & & 5 & & & 5 \\
\hline & retrieved fabellae & & & 5 & & & 5 \\
\hline & patellae & 1 & & 4 & & & 5 \\
\hline & metatarsals & & & 5 & 1 & 1 & 3 \\
\hline & tarsal joint bones & & & 5 & 2 & & 3 \\
\hline & acetabula & 1 & 2 & 2 & & 5 & \\
\hline & prox femur \& articular & 4 & & 1 & 5 & & \\
\hline & femoral shaft & 4 & & 1 & 3 & & 2 \\
\hline & distal femur \& articular & 5 & & & 5 & & \\
\hline & prox tibia \& articular & 4 & & 1 & 5 & & \\
\hline & tibial shaft & 3 & & 2 & 3 & & 2 \\
\hline & distal tibia \& articular & 5 & & & 5 & & \\
\hline & prox fibula \& articular & 5 & & & 5 & & \\
\hline & fibular shaft & 2 & & 3 & 2 & & 3 \\
\hline & distal fibula \& articular & 5 & & & 5 & & \\
\hline Appendicular Skeleton & phalanges & & & 5 & 1 & 1 & 3 \\
\hline \multirow[t]{14}{*}{ left, right forelimbs } & nails & & & 5 & & & 5 \\
\hline & metacarpal bones & & & 5 & & 1 & 4 \\
\hline & retrieved sesamoids & & & 5 & & & 5 \\
\hline & carpal joint bones & & & 5 & & & 5 \\
\hline & scapula articular & 2 & 3 & & 3 & 2 & \\
\hline & prox humerus \& articular & 3 & 1 & 1 & 3 & 1 & 1 \\
\hline & humeral shaft & 4 & & 1 & 4 & & 1 \\
\hline & distal humerus $\&$ articular & 3 & & 2 & 5 & & \\
\hline & prox radius \& articular & 3 & & 2 & 4 & 1 & \\
\hline & radial shaft & 3 & & 2 & 5 & & \\
\hline & distal radius \& articular & 5 & & & 5 & & \\
\hline & prox ulna \& articular & 4 & & 1 & 3 & 1 & 1 \\
\hline & ulnar shaft & 3 & & 2 & 3 & & 2 \\
\hline & distal ulna \& articular & 5 & & & 5 & & \\
\hline
\end{tabular}

OP = overt pathology, IP = incipient pathology, $\mathrm{N}=$ normal

*some small bones were not retrieved from all individuals after skeletal clearing 


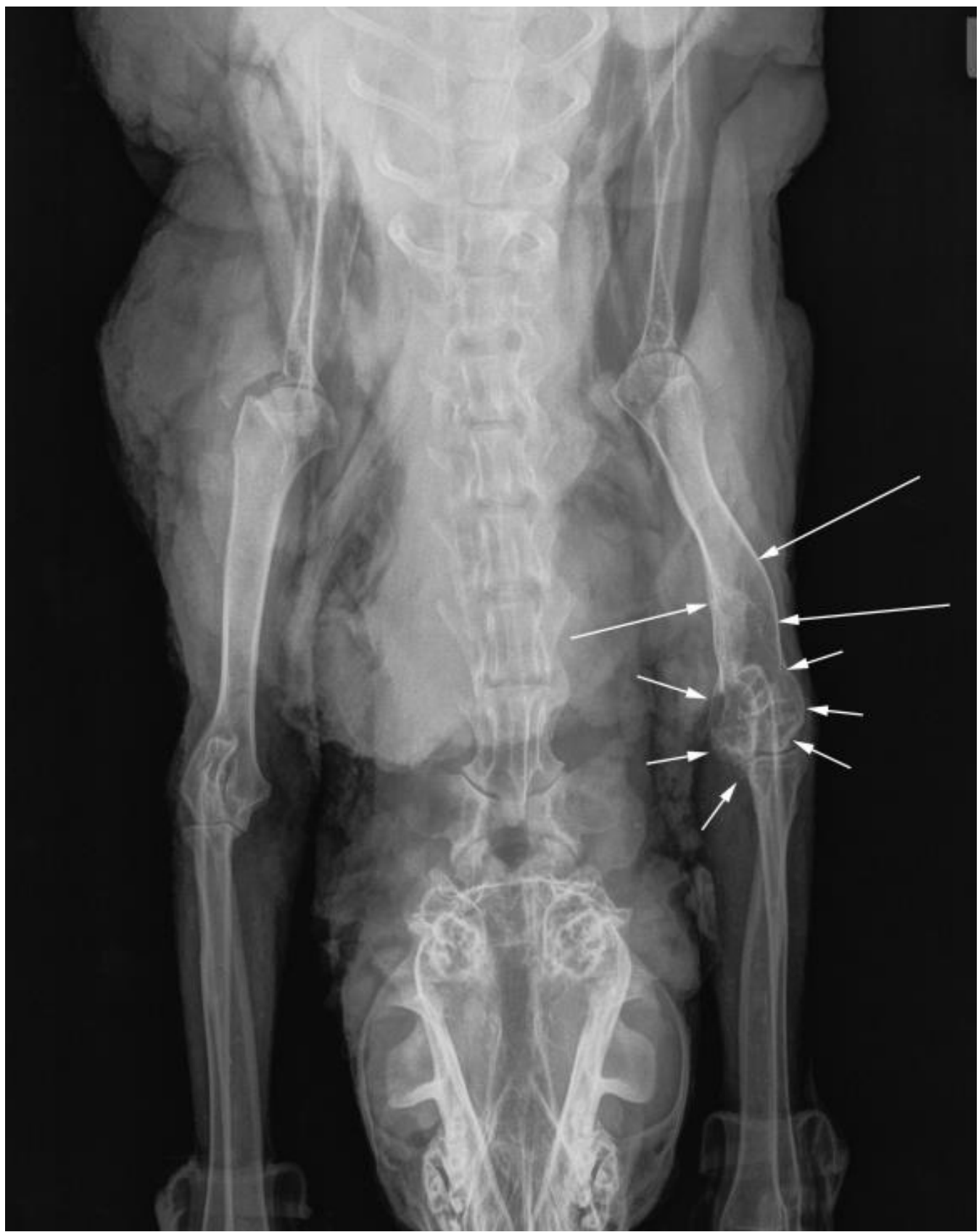

Fig (1): Dorsoventral forelimbs of more obese fox 42 . Note the healing fracture of the distal aspect of the left humerus (long arrows) and the associated degenerative joint disease of the elbow (short arrows). 


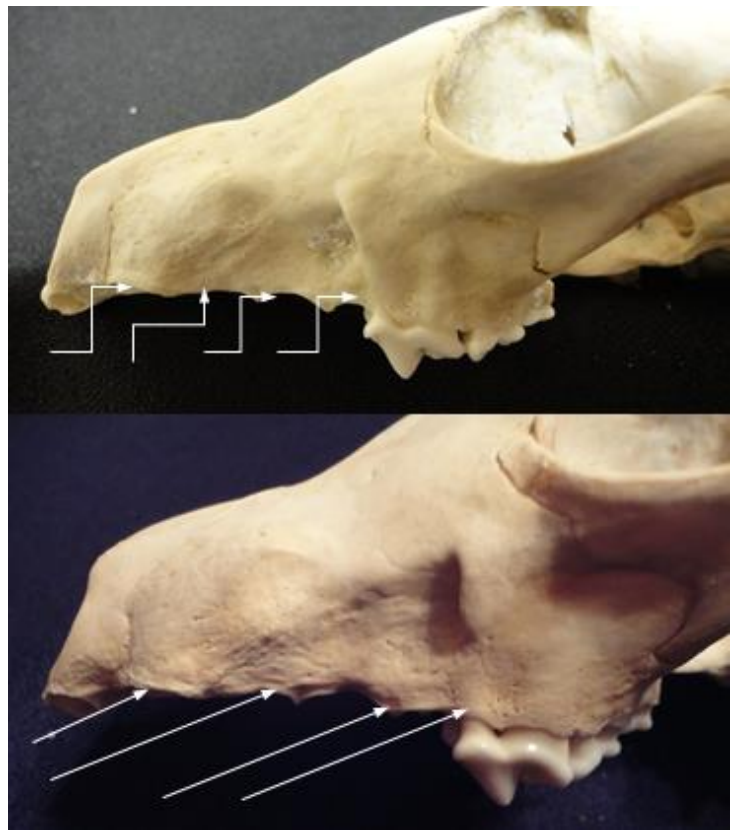

Fig (2): Top photo: Normal alveolar margins in left maxilla of less obese fox 20 (stepped arrows). Bottom photo: Mildly prominent alveolar margins in left maxilla of more obese fox 42 (straight arrows).

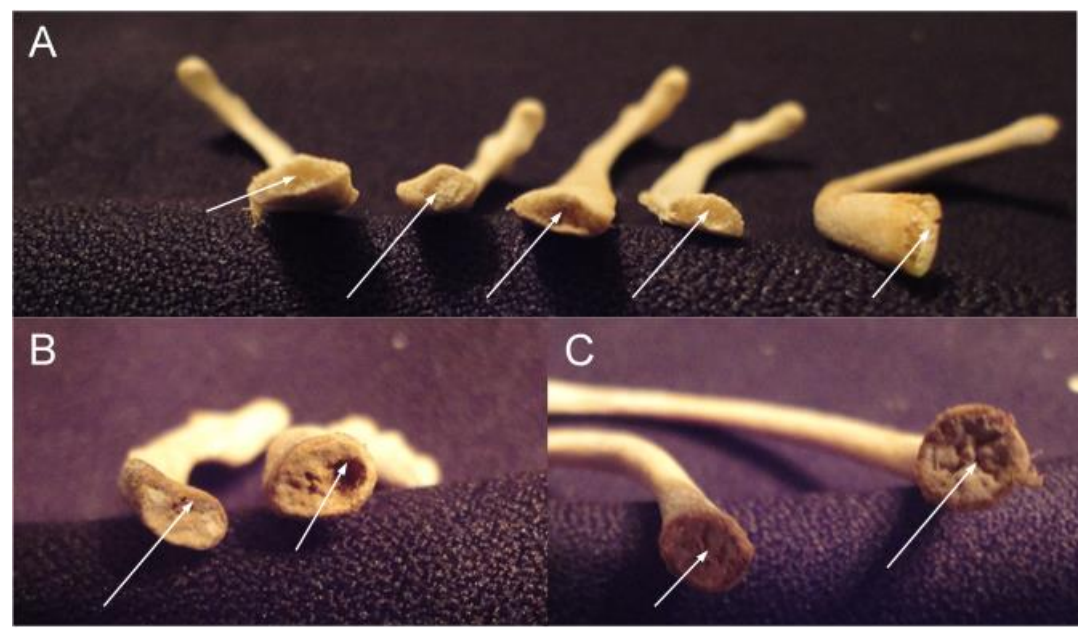

Fig (3): End-on view of costochondral junctions, rib cross-sectional aspect. (A) Less obese fox 10, all normal (arrows); (B) More obese fox 42, left is moderately affected; right is severely affected (arrows); and (C) More obese fox 42, both severely affected (arrows). 

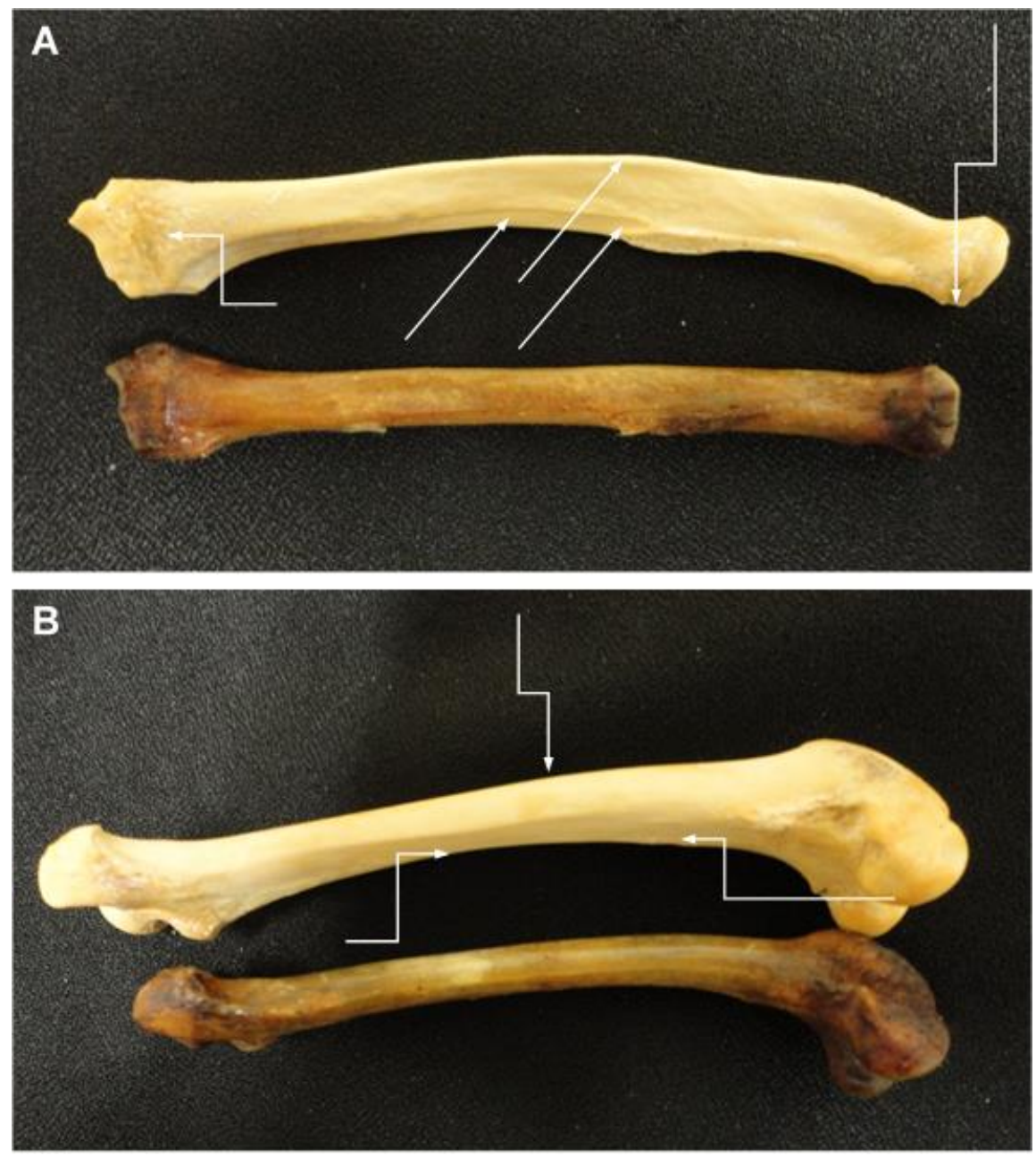

Fig (4): (A) Right radius, ulnar view (top) of more obese fox 12, compared with an adult arctic fox 615858 (Illinois State Museum zoology collections); distal is to the left. The more obese fox shows large size, severe mid-shaft curvature to medial (straight arrows), rough-surfaced distal epiphyseal and metaphyseal bone (short stepped arrow), and mild lateral prominence proximal periarticular margin (long stepped arrow). The bone of the wild fox is normal.

(B) More obese fox 12 right lateral femur (top), compared with arctic fox 615858 specimen. Distal is to the right. The more obese fox shows mildly increased mid-shaft curvature towards cranial (long stepped arrows). 

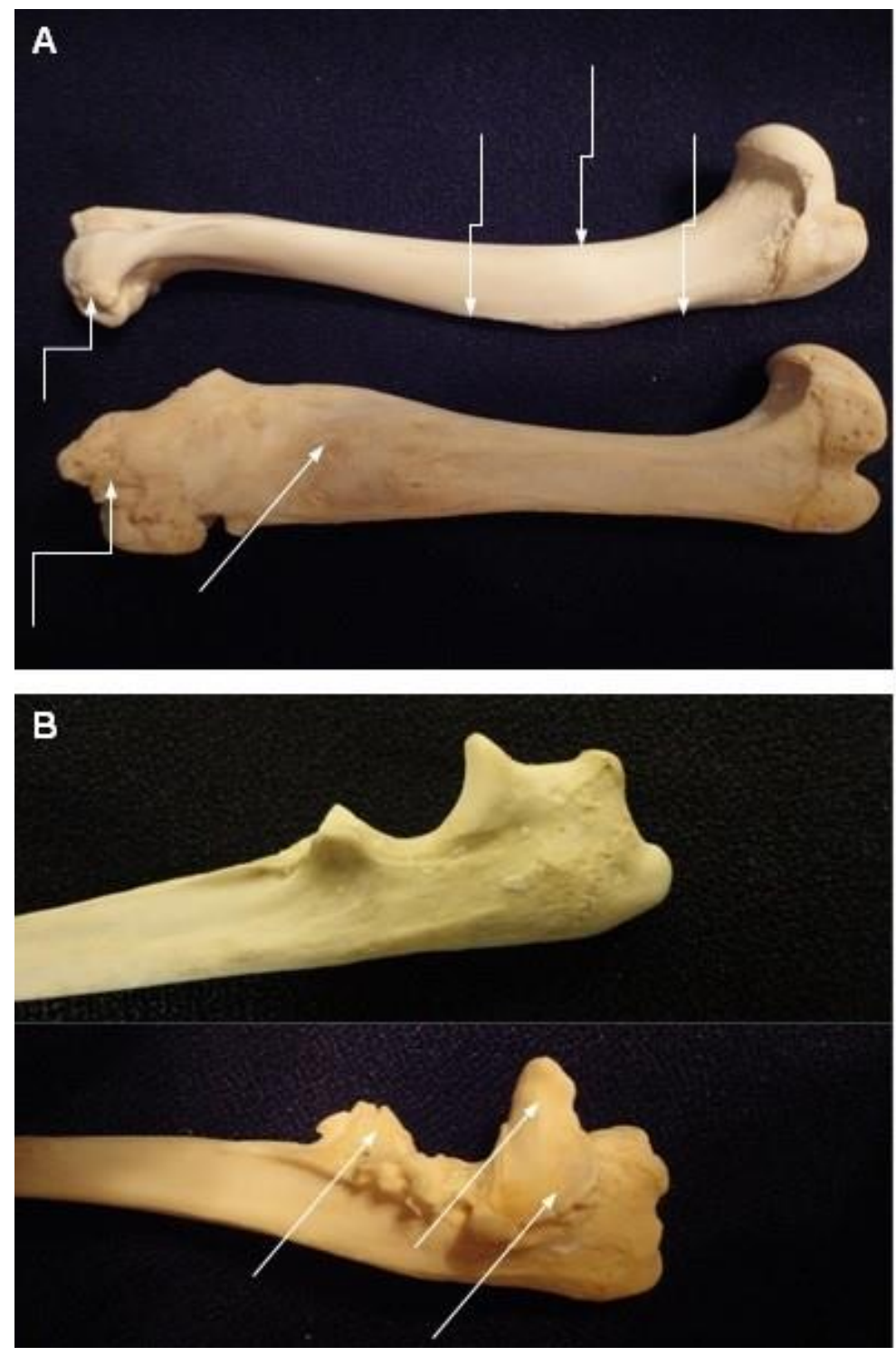

Supplementary Fig S1: (A): Right (top) and left (bottom) humerus of more obese fox 42; distal is to the left. The right humerus shows mild excess curvature to cranial at upper mid-shaft (long stepped arrows), with mild prominence of articular margin and periarticular features distally (short stepped arrow). The left humerus has a healed distal shaft pathological fracture (straight arrow) with bone thickening and remodelling. Distal articular features are deformed by osteophyte production secondary to humeral fracture-associated elbow joint deformity (stepped arrow). (B): The left proximolateral ulna of less obese fox 42 (bottom) displays very severe osteophyte production, secondary to humeral fracture and joint remodelling (arrows). 


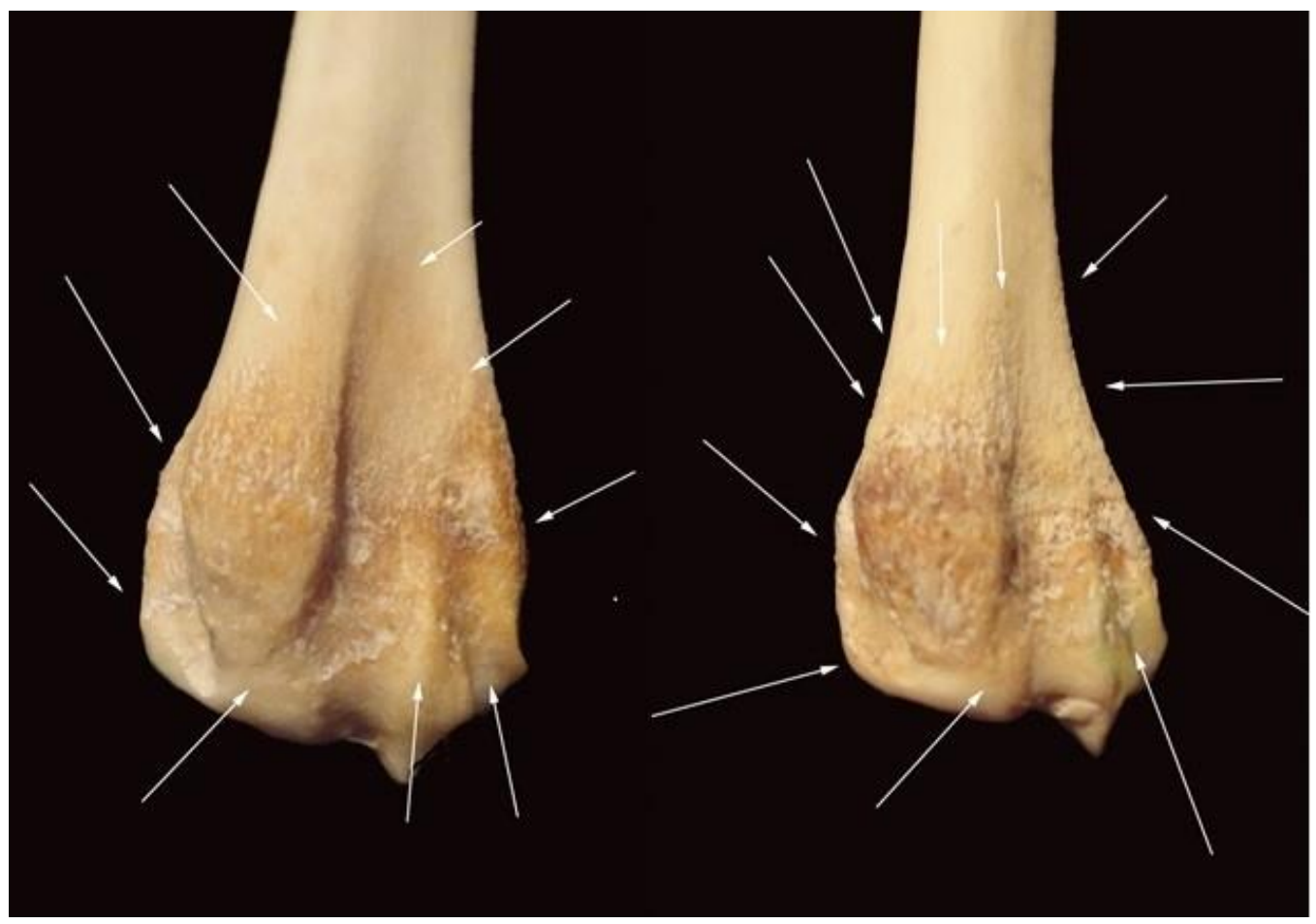

Supplementary Fig S2: Distal right radius, demonstrating mild (left: more obese fox 52) and severe rough bone (right; less obese fox 20) on epiphyseal and metaphyseal bone surfaces (arrows). 

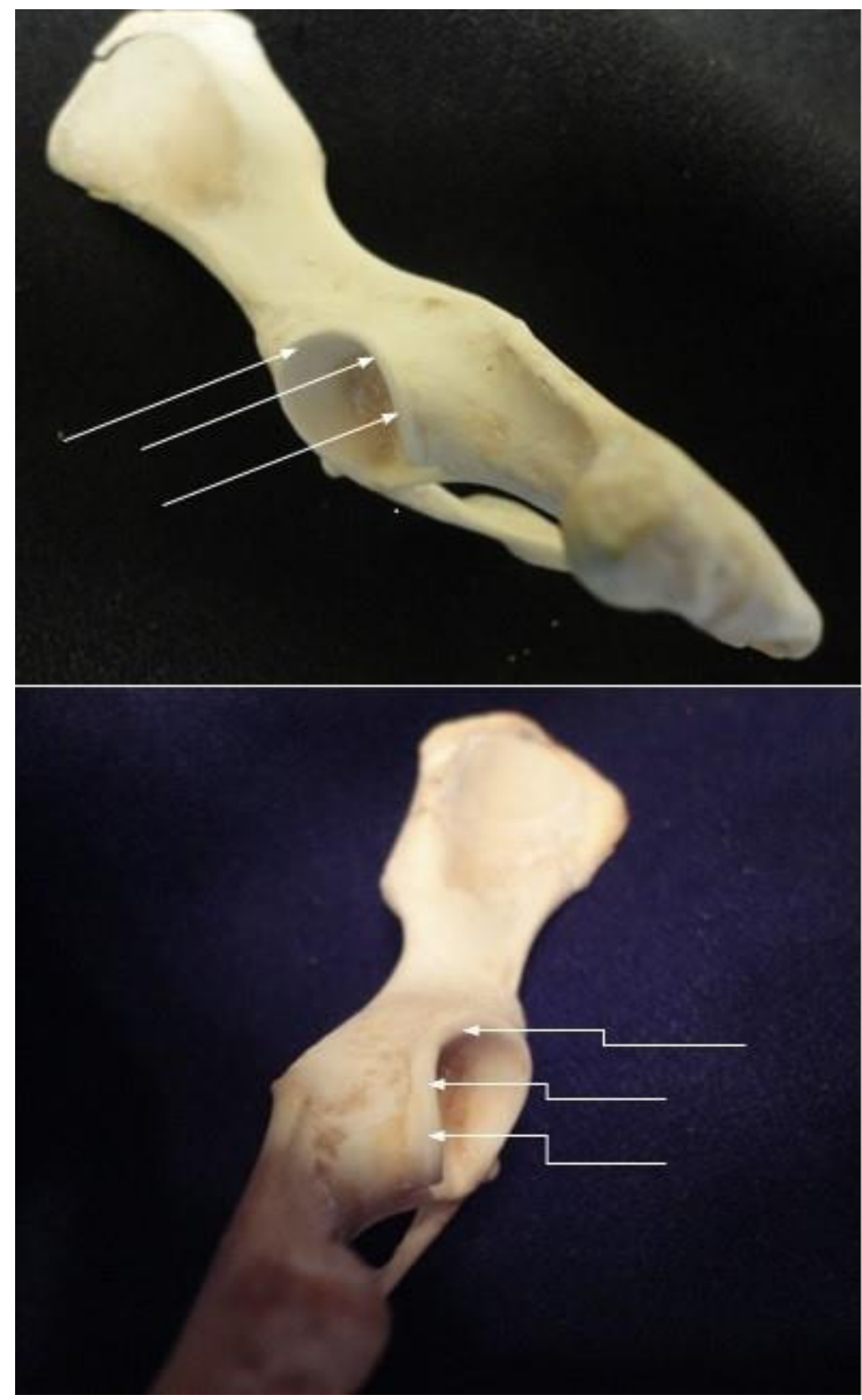

Supplementary Fig S3: Top photo: Straight arrows indicate lateral articular margin prominence that is normal in most foxes (example from less obese fox 50). Bottom photo: Stepped arrows indicate lateral articular margin prominence that represents mild-moderate increase, suggesting smooth osteophyte production in more obese fox 42. 


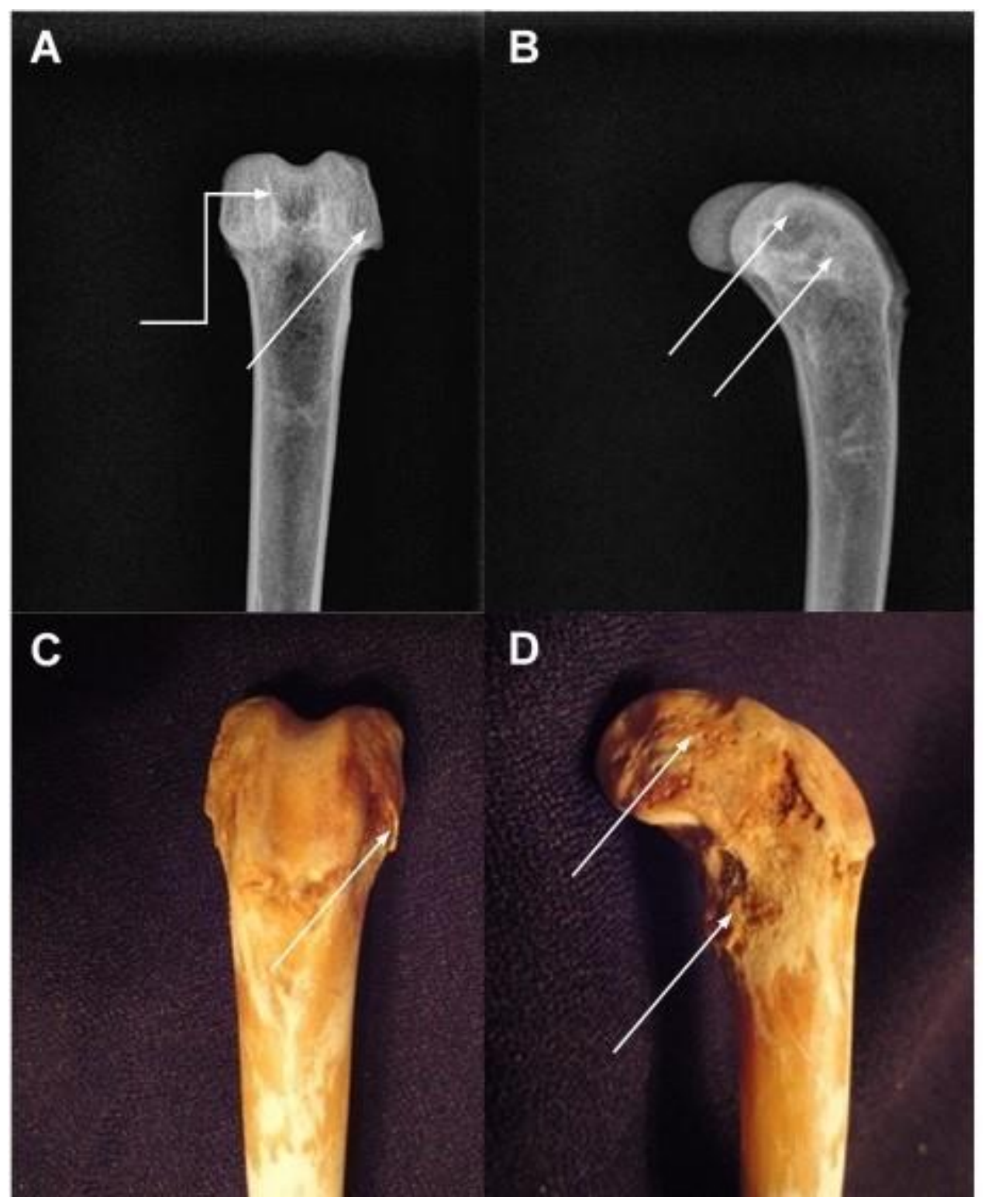

Supplementary Fig S4: Comparison of radiographs and dry bone, distal left femur of more obese fox 42. (A): Distal left femur, cranio-caudal radiograph; (B): Distal left femur, latero-medial radiograph; (C): Gross photo cranial; and (D): Gross photo lateral. Epiphyseal and metaphyseal bone has rough surfaces on all sides, and both condyles reveal porosity-associated superficial bone loss (straight arrows). The lateral intercondylar articular margin is unusually prominent (A; stepped arrow). Articular surfaces are normal. 